\title{
Local Immiscibility Control on Shape and Size of Nano-Objects in Solvo-Thermal Process: Implications for Ferroelectric Nano-Particles
}

\author{
Christine Bogicevic* and Pierre-Eymeric Janolin* \\ Université Paris-Saclay, CentraleSupélec, CNRS, laboratoire SPMS, 91190 Gif-sur-Yvette, \\ France \\ E-mail: christine.bogicevic@centralesupelec.fr; pierre-eymeric.janolin@centralesupelec.fr
}

\begin{abstract}
Solvo-thermal synthesis is an effective method to obtain ferroelectric nano-particles. The morphology and size of these nano-particles dramatically impact the dielectric, ferroelectric, piezoelectric, optical properties of these materials at the nanoscale. This is of primary importance for miniaturized electro-active devices based on these materials. Herein, we propose to harness the full potential of water-ethanol mixture solvents to control the shape and size of nano-particles of a model ferroelectric, barium titanate. To take advantage of the local inhomogeneities that exist even in fully miscible liquids such as water and ethanol, we use a barium precursor that is only soluble in water together with a titanium precursor that is present in both components. Indeed, ethanol having hydrophilic and hydrophobic parts the two liquids remain distinct at the local scale. A threshold molar fraction exists at $\mathrm{x}_{\mathrm{EtOH}}=0.3$ in water-ethanol mixtures; below this threshold, the water H-bonds network percolates throughout the sample whereas above water forms clusters that act as "nano-reactors". If below the concentration
\end{abstract}


threshold SEM images reveal that only elongated shapes (at best mixed with nanospheres) are obtained, just above the threshold, nano-tori and nano-cubes are observed; even further above the threshold, the reaction is limited to the aggregation-nucleation stage and only nano-cubes are obtained. This illustrates the fact that, in solvo-thermal syntheses, when the solvent is a mixture and one the reactant is confined in one of the constituents of the solvent, it is possible to control the morphology and size of the synthesized nano-objects.

\section{Keywords}

nano-objects, solvo-thermal synthesis, hydrothermal synthesis, solvent, ferroelectrics

\section{Introduction}

The control of the size and morphology of nano-objects is of crucial importance to their use in everything from drugs, cosmetics, eyeglasses, paints to fundamental research.1 ${ }^{14}$ Ferroelectric nano-particles, in particular, have been extensively studied both theoretically and experimentally as they offer a route to engineer their dielectric, ferroelectric or piezoelectric, energy storage $\mathrm{e}^{\sqrt{5}}$ properties by controlling the radius of nano-spheres. ${ }^{[6]}$ In addition, various shapes have been reported and/or calculated, such as nano-wires, ${ }^{7]}$ nano-tori, ${ }^{[8] 9}$ hysterons, ${ }^{10}$ solid or hollow spheres, $\frac{11}{11}$ leading e.g., for nano-tori, to the prediction of a novel order parameter (the hypertoroidal moment ${ }^{12}$ ). Such nano-objects are often synthesized in a solvent, by hydrothermal or sol-gel techniques. Traditionally, the parameters used to control the size and morphology of nano-objects are chemical (precursor, concentration) or physical (temperature). A different approach is presented here, where it is instead the solvent that provides the control of the size and morphology. To do so, the solvent must be a mixture of at least two liquids and one of the reactants has to be soluble in only one of the liquids. This is possible because even miscible liquids remain heterogeneous at the nano-scale and this 
heterogeneity can be used to localise and control the chemical reaction through the solvent composition.

We show that, at fixed quantities of reactants, the solvent composition controls the synthesis of barium titanate $\left(\mathrm{BaTiO}_{3}\right)$ nano-cubes, nano-tori, nano-spheres in "nano-reactors" of set molarities. $\mathrm{BaTiO}_{3}$ is a model, structurally simple, ferroelectric perovskite oxide that has been studied since the 1940 s. It is one of the key lead-free ferroelectrics ${ }^{13}$ and is used as an end-member in many lead-free relaxor ferroelectric solid solutions $\frac{14 \mid 15}{15}$ that exhibit large energy storage potential, $\stackrel{16}{,}$ large dielectric properties, and large strain under electric field. 17 We also explain the relative contribution of other synthesis parameters such as temperature and pressure, as well as the reaction advancement throughout the synthesis process. Such approach is readily transferable to other solvents, other materials, and other solvent-based synthesis techniques. It is anticipated to enable e.g. the production of nano-spheres of pharmaceutical interest by solvo-thermal synthesis.

In solution-based synthesis techniques, solvents are rarely thought of as playing a decisive role. In sol-gel and freeze-drying syntheses, the solvent is used as a complexing agent, otherwise its role is merely to provide a liquid environment, insuring the homogeneous mixture of reactants, especially in small quantities. There is nevertheless great potential in exploiting the solvent properties: its polarity in sol-gel syntheses enable to obtain shape-controlled $\mathrm{ZnO}$

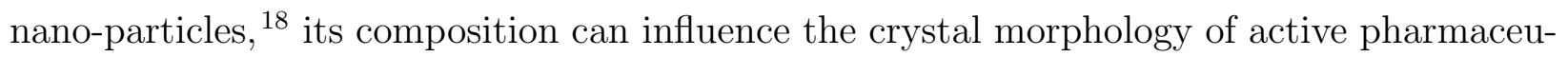
tical ingredients in solution crystallization, $\frac{19}{19}$ or control the shape of Rhodium particles in polyol synthesis. 20

Here, we present a novel approach using the solvent to control the morphology and size of nano-particles of a functional material, $\mathrm{BaTiO}_{3}$, synthesized by solvo-thermal process. This approach is based on the physico-chemical properties of water-ethanol mixtures. Even though these two liquids are fully miscible, their mixture does not constitute a homogeneous third solvent at the nano-scale.

The key parameter to the approach is ensuring that one of the reactants is only soluble 
in water and not in ethanol. This enables control of the final morphology and size of the nano-structures through the tuning of the water-to-ethanol ratio. Such control enables the reproducible synthesis of nano-spheres, nano-cubes and nano-tori of $\mathrm{BaTiO}_{3}$.

\section{Results and discussion}

\section{Synthesis and characterization of $\mathrm{BaTiO}_{3}$ nano-structures}

$\mathrm{BaTiO}_{3}$ nano-structures are synthesized by solvo-thermal process from barium precusors only soluble in water and solid titanium precursors that are present in both water and ethanol. The solvo-thermal syntheses are carried out with various volume fractions of water and at three temperatures: $150^{\circ} \mathrm{C}, 200^{\circ} \mathrm{C}$, and $250^{\circ} \mathrm{C}$, under autogenous pressure. The purity of the products is verified by X-ray diffraction and their size and morphology investigated by scanning electron microscopy.

\section{Synthesis of $\mathrm{BaTiO}_{3}$ and solvents}

The barium precursor, $\mathrm{Ba}(\mathrm{OH})_{2} \cdot 8 \mathrm{H}_{2} \mathrm{O}$, (Alfa Aesar 98+\%) is only soluble in water and serves as the barium source for the synthesis of $\mathrm{BaTiO}_{3}$. The titanium precursor, $\mathrm{Na}_{2} \mathrm{Ti}_{3} \mathrm{O}_{7}$, comes in the form of solid uniform layered nano-rods. It is present in both the water and ethanol parts of the solvent and acts as the source of titanium for the synthesis of $\mathrm{BaTiO}_{3}$.

The $\mathrm{Na}_{2} \mathrm{Ti}_{3} \mathrm{O}_{7}$ nano-rods are build from two-dimensional framework of $\mathrm{TiO}_{6}$ octahedra with an interlayer space filled by sodium atoms. ${ }^{21}$ This form has been preferred over the macroscopic powders of titanium as the latter would make the identification of the final shape of the products more complicated. ${ }^{22}$ To synthesize the $\mathrm{Na}_{2} \mathrm{Ti}_{3} \mathrm{O}_{7}$ nano-rods, $\mathrm{TiO}_{2}$ anatase (Alfa Aesar 99.9\%) is dispersed in $10 \mathrm{M} \mathrm{NaOH}$ aqueous solution to obtain a concentration of Ti of $2.7 \cdot 10^{-1} \mathrm{M}$ by stirring for $1 \mathrm{~h} 30$. The filling factor of the autoclave is 0.7 . After sealing, the autoclave is heated at $200^{\circ} \mathrm{C}$ for three days and then cooled to room temperature. The precipitate is collected, washed with de-ionized water until the $\mathrm{pH}$ of the filtrate is neutral. 
The precipitate is finally collected in ethanol and dried at $70^{\circ} \mathrm{C}$ for $12 \mathrm{~h}$.

Figure 1 shows XRD pattern and SEM images of the $\mathrm{Na}_{2} \mathrm{Ti}_{3} \mathrm{O}_{7}$ nano-rods, used for the synthesis of $\mathrm{BaTiO}_{3}$ nano-structures. The XRD pattern (panel (a) Figure 11) matches the standard XRD pattern (JCPDS No31-1329 for $\mathrm{Na}_{2} \mathrm{Ti}_{3} \mathrm{O}_{7}$ ). The SEM image shows pure $\mathrm{Na}_{2} \mathrm{Ti}_{3} \mathrm{O}_{7}$ nano-rods (panel (b) Figure 1) with a diameter of less than $200 \mathrm{~nm}$ and ten micrometers length.

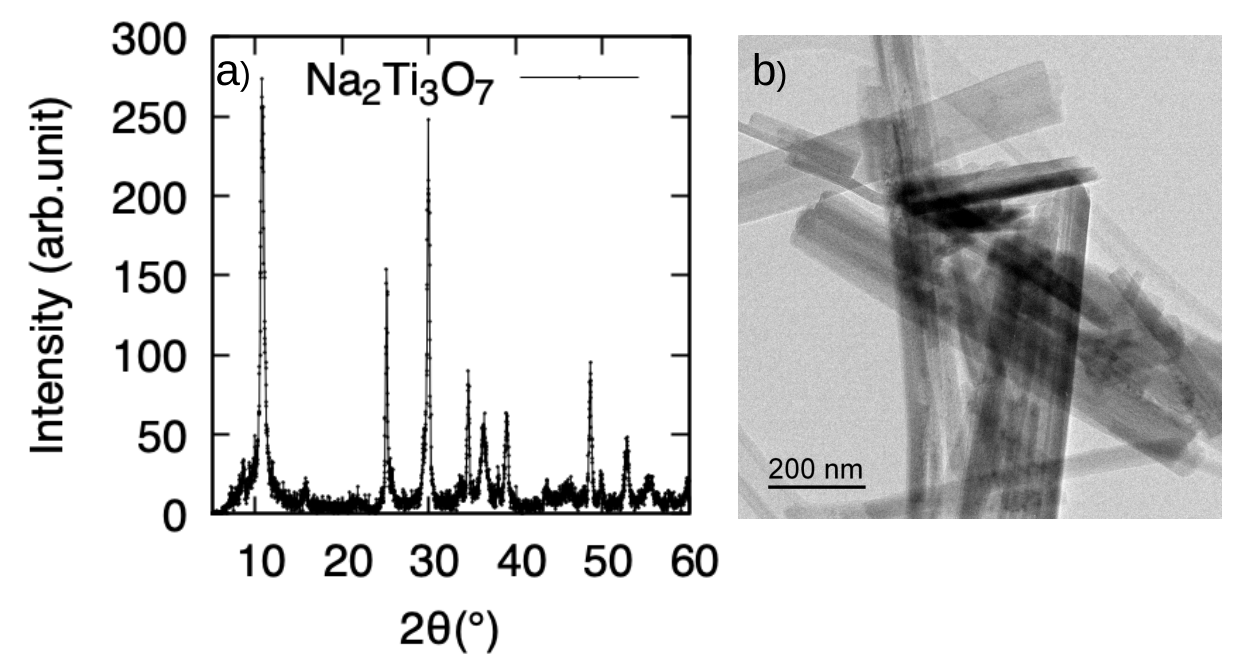

Figure 1: a) XRD pattern and b) SEM image of $\mathrm{Na}_{2} \mathrm{Ti}_{3} \mathrm{O}_{7}$ nano-rods

The barium titanate syntheses (see Supporting Information) are initiated by mixing barium and titanium precursors in a $1.1 \mathrm{Ba} / \mathrm{Ti}$ molar ratio with the necessary quantity of solvent (denoted ExW100-x with Ex and W100-x the volume fractions of ethanol and water respectively) which may be absolute ethanol (E100W0), de-ionized water (E0W100), or a mix with the following volume ratios: 30\% (E30W70), 60\% (E60W40), and 80\% (E80W20) of ethanol. In this way, solutions of $\mathrm{Ba}(\mathrm{OH})_{2}$ ranging from 0.1 to $7 \mathrm{M}$ can be prepared depending on the water volume fraction included in the solution (Equation S1). The solvo-thermal syntheses of $\mathrm{BaTiO}_{3}$ are performed at $150^{\circ} \mathrm{C}, 200^{\circ} \mathrm{C}$, or $250^{\circ} \mathrm{C}$ under autogenous pressure for $24 \mathrm{~h}$. 


\section{Characterization of $\mathrm{BaTiO}_{3}$ nano-structures}

\section{Purity of the products}

All diffraction patterns of the samples synthesized with the different solvents at 150, 200 or $250^{\circ} \mathrm{C}$ for 24 hours (see Figure $\mathrm{S} 2$ ) are indexed with the room-temperature tetragonal structure of $\mathrm{BaTiO}_{3}\left(\mathrm{JCPDS} \mathrm{N}^{\circ} 05-626\right)$. Diffraction patterns are recorded systematically on the as-obtained samples, i.e. without acidic treatment, so as to detect any residual $\mathrm{BaCO}_{3}$, to estimate their purity, and to enable meaningful comparison.

Increasing temperature decreases the residual $\mathrm{BaCO}_{3}$ which can be fully eliminated from the products through an acidic treatment 23 . This highlights the importance of both eliminating the carbon source in the solvent apart from that remaining in the air $\left(\mathrm{CO}_{2}\right)$ trapped in the vessel and to use a $1.1 \mathrm{Ba} / \mathrm{Ti}$ molar ratio in order to avoid sub-stoichiometric $\mathrm{BaTiO}_{3}$ syntheses.

During the solvo-thermal synthesis of $\mathrm{BaTiO}_{3}$ nano-particles two simultaneous mechanisms take place 24 . The first is a deposition reaction of the $\mathrm{Ba}^{2+}$ ions with a local dissolution on the surface of the titanium precursor followed by in situ precipitation of $\mathrm{BaTiO}_{3}$ nano-

crystals. ${ }^{24 \mid 25}$ The second is the in situ topotactic ion exchange between $\mathrm{Na}^{+}$and $\mathrm{Ba}^{2+}$ inside the layered titanium precursor enabling the reaction between $\mathrm{Ba}^{2+}$ and $\mathrm{TiO}_{6}$ octahedra that occurs simultaneously. ${ }^{24}$ This is illustrated on Fig,2

The consumption of the titanium precursor $\left(\mathrm{Na}_{2} \mathrm{Ti}_{3} \mathrm{O}_{7}\right)$ to form $\mathrm{BaTiO}_{3}$ is completed at $150^{\circ} \mathrm{C}$ except for the absolute ethanol solvent (E100W0) (see Figure S2). This is because the barium precursor, $\mathrm{Ba}(\mathrm{OH})_{2} \cdot 8 \mathrm{H}_{2} \mathrm{O}$, is insoluble in pure ethanol but easily soluble into water. In the E100W0 only $8 \mathrm{H}_{2} \mathrm{O}$ per precursor molecules are available for the dissolution. Very small amount of residual $\mathrm{BaCO}_{3}$ remain especially in the pure water solvent (E0W100). However, increasing the temperature to $200^{\circ} \mathrm{C}$ reduces this trace contamination. 


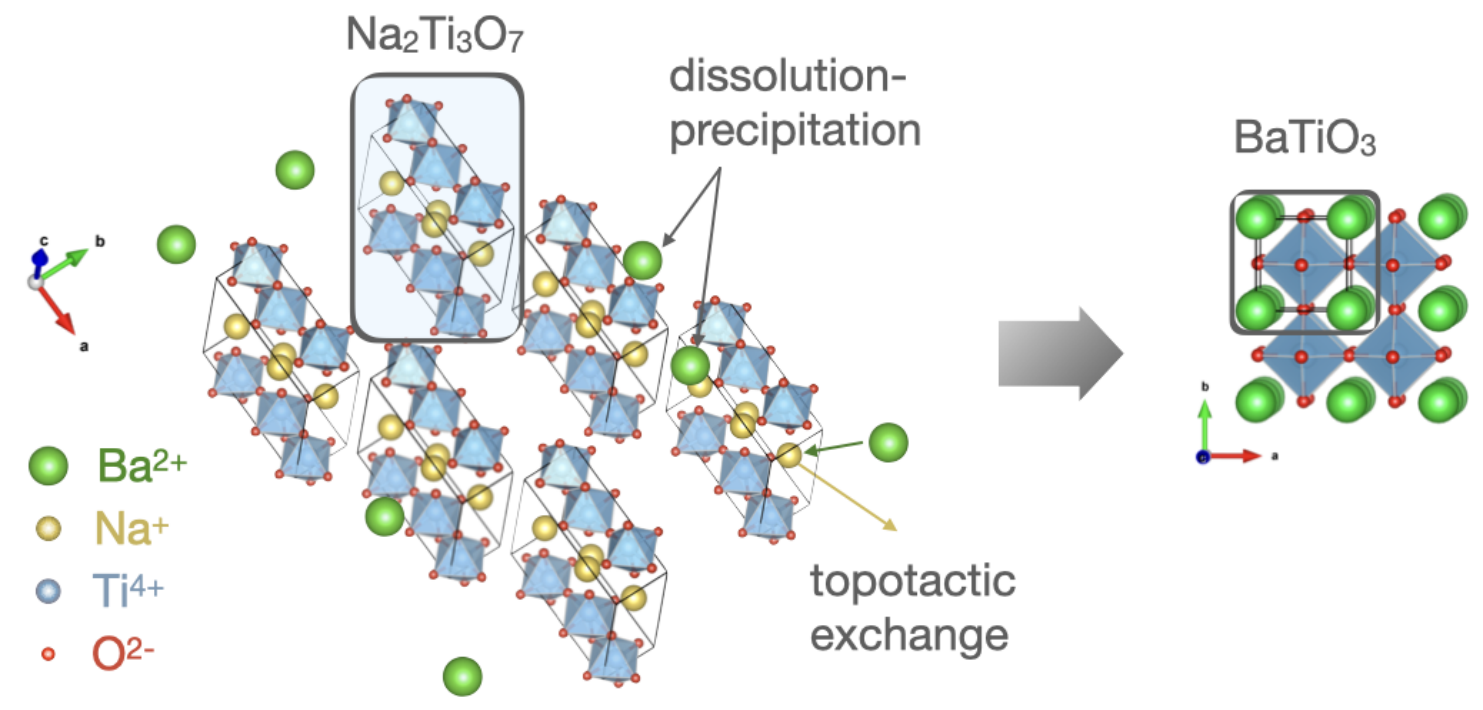

Figure 2: Scheme of the reaction mechanism leading to the synthesis of $\mathrm{BaTiO}_{3}$ through simultaneous dissolution-precipitation and topotactic exchange between $\mathrm{Na}^{+}$and $\mathrm{Ba}^{2+}$ ions inside the layers of the Ti precursor. 


\section{Morphology and Size of the Nano-structures}

The morphology of the as-obtained $\mathrm{BaTiO}_{3}$ products is observed by scanning electron microscopy (SEM, Figure 3). Each sample is identified with a label indicating the maximum temperature followed by the solvent composition. For all solvent compositions (except pure water, at $150^{\circ} \mathrm{C}$ ), the SEM images show that the entire surface originally belonging to the $\mathrm{Na}_{2} \mathrm{Ti}_{3} \mathrm{O}_{7}$ nano-rods, is fully composed of aggregated $\mathrm{BaTiO}_{3}$ nano-particles of about 10$50 \mathrm{~nm}$ in size. In pure ethanol (and only at $150^{\circ} \mathrm{C}$ ) some non-reacted $\mathrm{Na}_{2} \mathrm{Ti}_{3} \mathrm{O}_{7}$ nano-rods remain, consistent with X-ray diffraction data (Figure S2). Importantly, all performed experiments involve identical amounts of reactants $\left(\mathrm{Ba}(\mathrm{OH})_{2} \cdot 8 \mathrm{H}_{2} \mathrm{O}\right.$ and $\left.\mathrm{Na}_{2} \mathrm{Ti}_{3} \mathrm{O}_{7}\right)$. The morphology of the $\mathrm{BaTiO}_{3}$ nano-structures varies from nano-spheres to nano-tori to agglomerated or individual nano-cubes, depending on the solvent used and the synthesis temperature, elongated shapes are also observed in pure water for all temperatures.

The observed shapes of the synthesized nano-particles are hence only due to the influence of temperature and solvent composition. Figure 3 shows that, for all solvents except pure water, the higher the temperature the more non-agglomerated the nano-objects.

Both X-ray diffraction and SEM imaging are used to determine the size of nano-objects. However, X-ray diffraction gives the apparent crystallite size via the Scherrer formula, whereas SEM measurements give the size of the nano-objects which can be poly- or monocrystalline. Both methods give similar results for up to a size of about $80 \mathrm{~nm}$ (i.e. for E100W0 and E80W20, see Figure S4) but as nano-objects become poly-crystalline, the apparent crystallite size calculated from X-ray diffraction becomes significantly smaller than the size of the nano-objects.

The size of the nano-particles increases with the water proportion of the solvent (Figure 4.a), from 10-40 nm for E100W0 to 280-330 nm for E0W100.

The fact that one of the precursor is soluble in only one of the solvent components is a key to obtain morphologies that differ from nano-spheres. In order to illustrate this point, we have carried out another experiment in E60W40 at $250^{\circ} \mathrm{C}$ for 24 hours but this time 

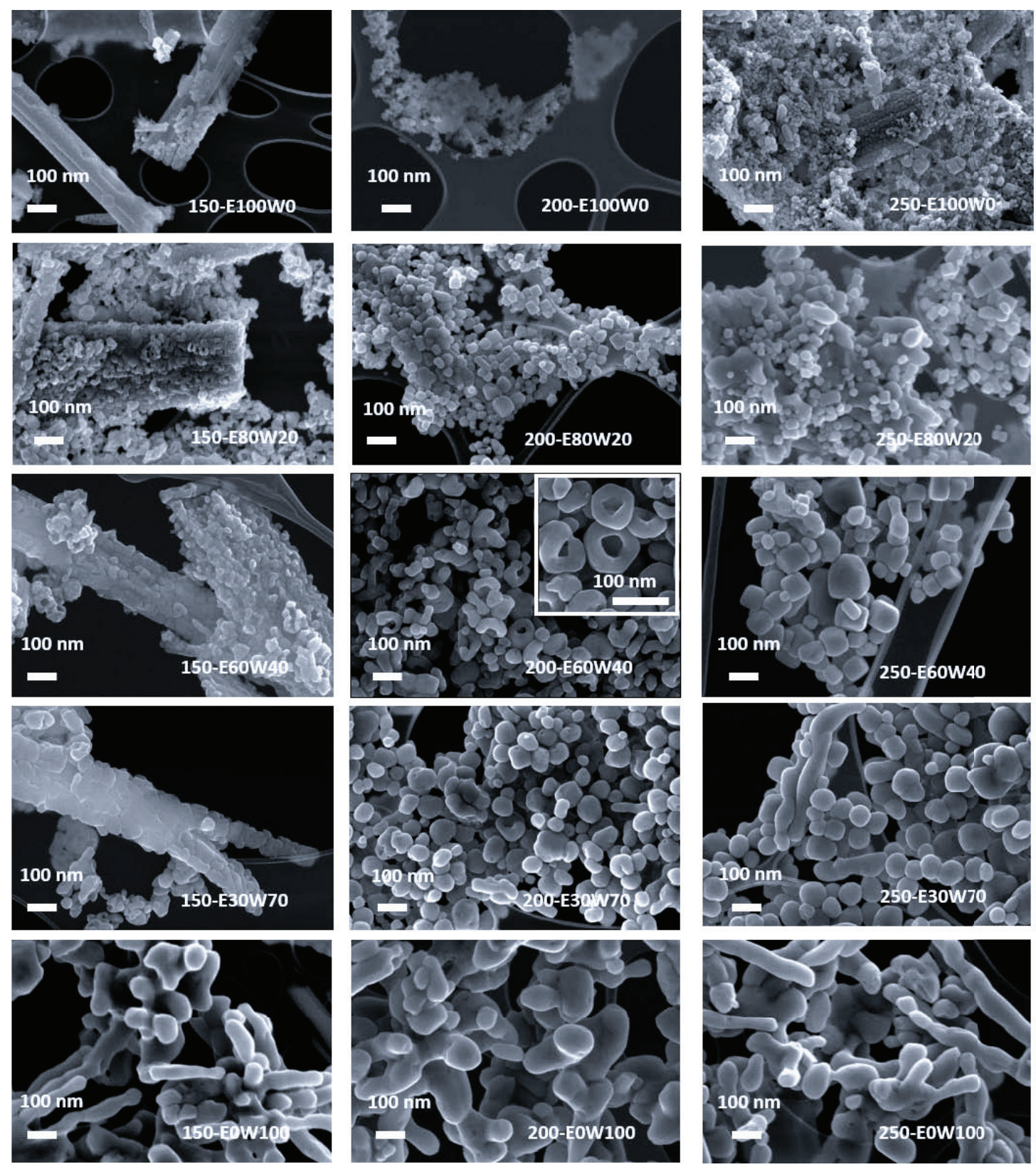

Figure 3: SEM images of the as-prepared $\mathrm{BaTiO}_{3}$ products obtained after 24 hours at $150^{\circ} \mathrm{C}$ (left column), $200^{\circ} \mathrm{C}$ (middle column) and $250^{\circ} \mathrm{C}$ (right column) for the various solvent compositions $(\mathrm{E} x \mathrm{~W} 100-x)$. 

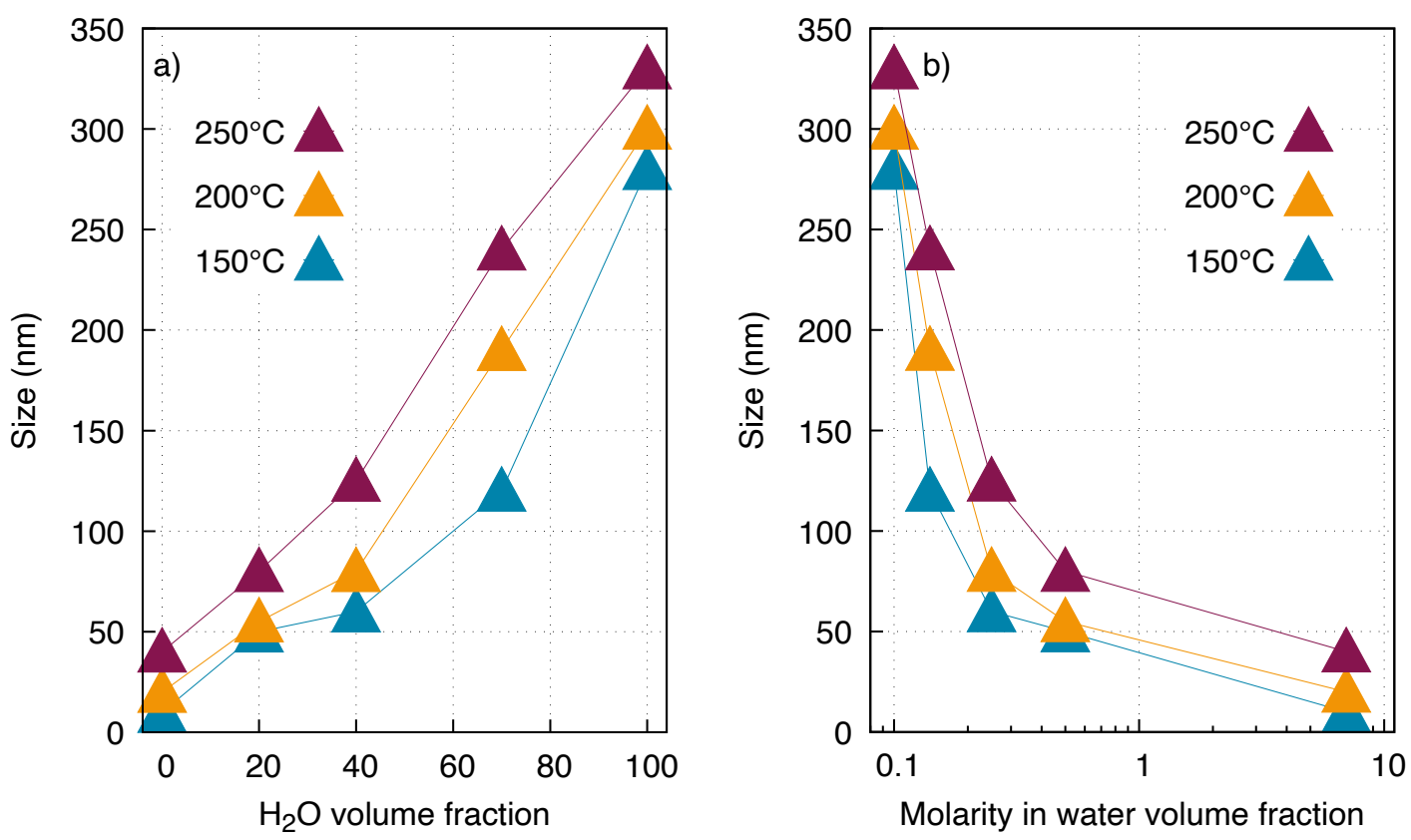

Figure 4: Size of the $\mathrm{BaTiO}_{3}$ nano-particles measured from the SEM images as a function of a) the water volume fraction and b) the molarity $\mathrm{M}$ in water volume fraction.

with $\mathrm{BaCl}_{2}$ as a barium precursor. $\mathrm{BaCl}_{2}$ is soluble both in water and in ethanol whereas $\mathrm{Ba}(\mathrm{OH})_{2} \cdot 8 \mathrm{H}_{2} \mathrm{O}$ is only soluble in water. With $\mathrm{BaCl}_{2}$, nano-spheres of about $100 \mathrm{~nm}$ in diameter are synthesized (see the SEM image in Fig.5) instead of nano-cubes from 50 to $300 \mathrm{~nm}$ in size (see Fig 3 with $\mathrm{Ba}(\mathrm{OH})_{2} \cdot 8 \mathrm{H}_{2} \mathrm{O}$.

\section{Identification of the main synthesis parameters}

The morphology of the $\mathrm{BaTiO}_{3}$ nano-structures varies from nano-spheres to nano-tori to nano-cubes depending on the solvent used and the synthesis temperature (see Figure 3). However, as these are solvo-thermal syntheses, pressure increases in the autoclave as it is heated. These three parameters (solvent composition, pressure, and temperature) are reviewed hereafter in order to evaluate their respective roles. 

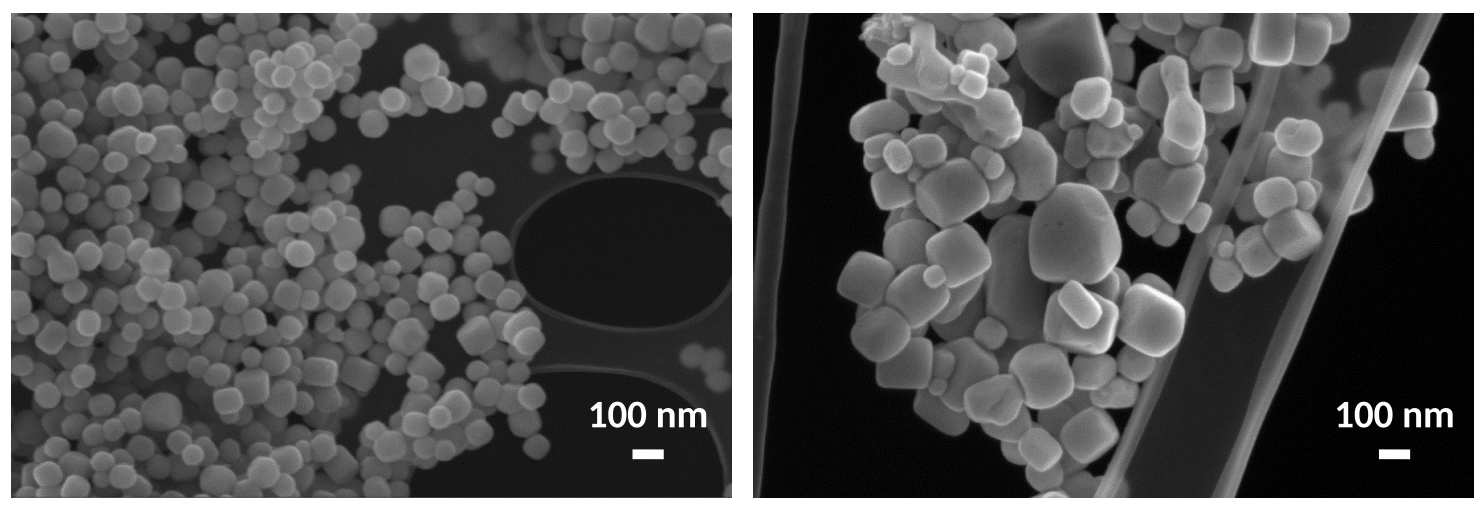

Figure 5: Comparison of the $\mathrm{BaTiO}_{3}$ nano-objects obtained at $250^{\circ} \mathrm{C}$ for 24 hours in E60W40 with $\mathrm{Na}_{2} \mathrm{Ti}_{3} \mathrm{O}_{4}$ nano-rods as Ti precursor: (left) nano-spheres obtained using $\mathrm{BaCl}_{2}$ as $\mathrm{Ba}$ precursor and (right) nano-cubes obtained using $\mathrm{Ba}(\mathrm{OH})_{2} \cdot 8 \mathrm{H}_{2} \mathrm{O}$ as $\mathrm{Ba}$ precursor. $\mathrm{BaCl}_{2}$ is soluble in water and ethanol whereas $\mathrm{Ba}(\mathrm{OH})_{2} \cdot 8 \mathrm{H}_{2} \mathrm{O}$ is only soluble in water, showing the importance of using a precursor that is soluble in only one components of the solvent.

\section{Solvent composition and molarity}

Since the barium precursor, $\mathrm{Ba}(\mathrm{OH})_{2} \cdot 8 \mathrm{H}_{2} \mathrm{O}$, is soluble only in water (and not in ethanol) and that its initial amount is the same for all solvents, the influence of the precursor concentration (molarity) relative to the water volume fraction (Table S1) rather than solvent composition should be considered. In this case, the size of the nano-particles decreases with increasing molarity in water volume fraction (Figure $4 \mathrm{~b}$ )).

In order to decouple the influence of molarity and solvent composition on the size and morphology of the synthesised nano-objects, an additional synthesis is performed where the solvent composition varies but not the molarity. This is achieved by adding barium precursor in a E0W100 solvent until its molarity is the same as in the E60W40 solvent. This molarity was chosen because of the very different shapes obtained at different temperatures in the E60W40 solvent with the regular amount of precursor. The X-ray pattern of this new synthesis is shown in Figure $\mathbf{S 5}$.

Both solvents produce agglomerated, spherical nano-particles at $150^{\circ} \mathrm{C}$ (left column in Figure 6) with larger sizes in pure water $\left(80 \mathrm{~nm}\right.$ vs $60 \mathrm{~nm}$ ). At $200^{\circ} \mathrm{C}$ (center column in Figure 6) the typical shape is a torus whereas at $250^{\circ} \mathrm{C}$ (right column in Figure 6) cubes are formed for both solvent compositions. This shows the prevalent role of molarity on the shape 
of the nano-objects. The composition of the solvent influences the size of the nano-objects, the pure water solvent producing larger nano-objects: the tori are two to three times larger at $200^{\circ} \mathrm{C}$ and the cubes nearly two and half time larger, with rounded edges, in pure water compared to the E60W40 solvent.
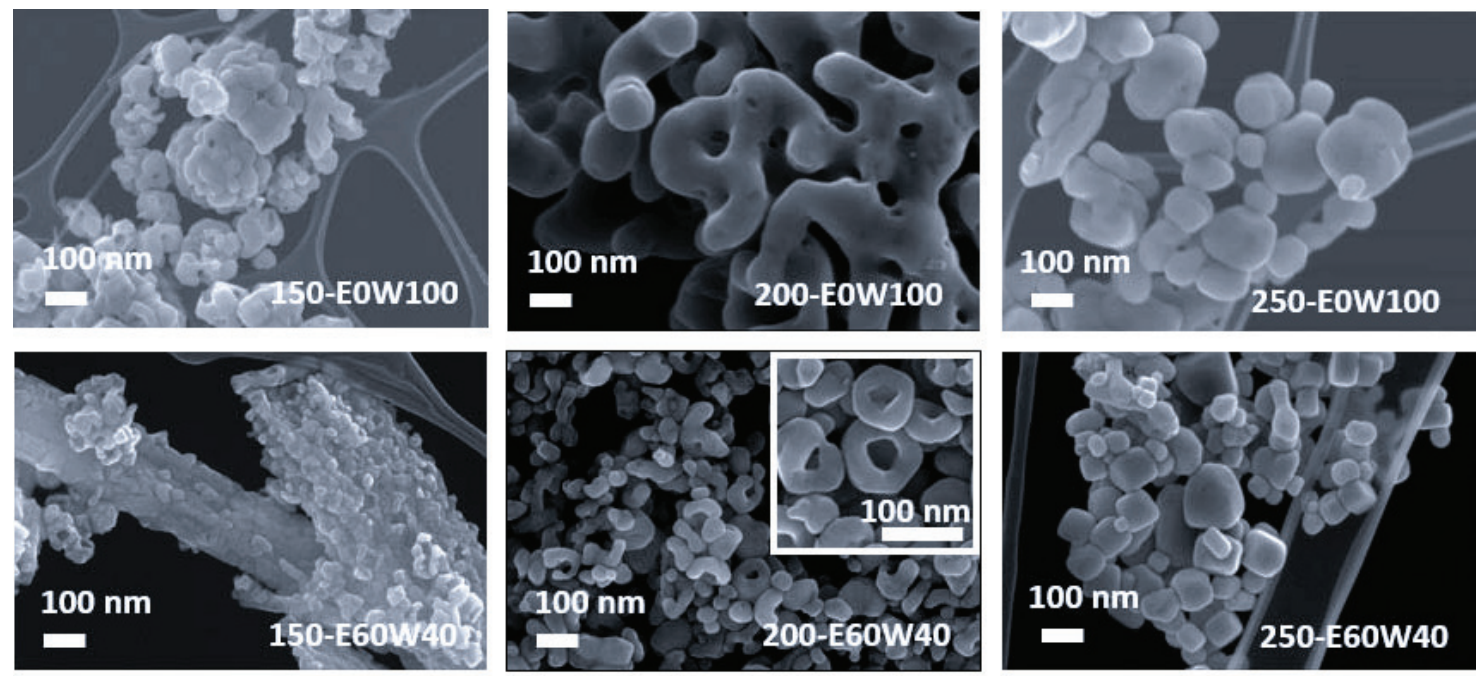

Figure 6: $\mathrm{SEM}$ images of the as-prepared $\mathrm{BaTiO}_{3}$ products obtained after 24 hours at $150^{\circ} \mathrm{C}$, $200^{\circ} \mathrm{C}$, and $250^{\circ} \mathrm{C}$. Top line: $0.25 \mathrm{M}$ aqueous solution (E0W100) and bottom line (middle row of Figure 3): 0.25M in the aqueous volume fraction of the solvent E60W40.

These results show that the molarity of precursors relative to the water content controls the morphology of the nano-objects whereas the solvent composition controls their size.

\section{Pressure}

In a solvo-thermal synthesis, pressure builds up as the autoclave is heated. Based on Raoult's and Dalton's laws of partial pressures, the equilibrium vapor pressure of an ideal mixture of two liquids (completely miscible in any proportion in the liquid and vapor states) is the sum of the partial pressures of its constituents weighted by their mole fractions. The autogenous pressure measured for pure solvents, i.e. without reactants (Figure 7) follows qualitatively Antoine equation using reference values for pure water and ethanol ${ }^{26}$ (see the dotted lines in Fig.7) but differs quantitatively, in particular for solvents E80W20, E60W40 and E30W70. This deviation shows that the actual pressure inside the vessel can only be estimated from 
reference values despite still following Antoine equation (see fits in Fig.7), especially as the experimental pressure also depends on the autoclave model and heating rate. ${ }^{27}$ At the end of the heating stage, during the dwelling time, no pressure variation is observed.
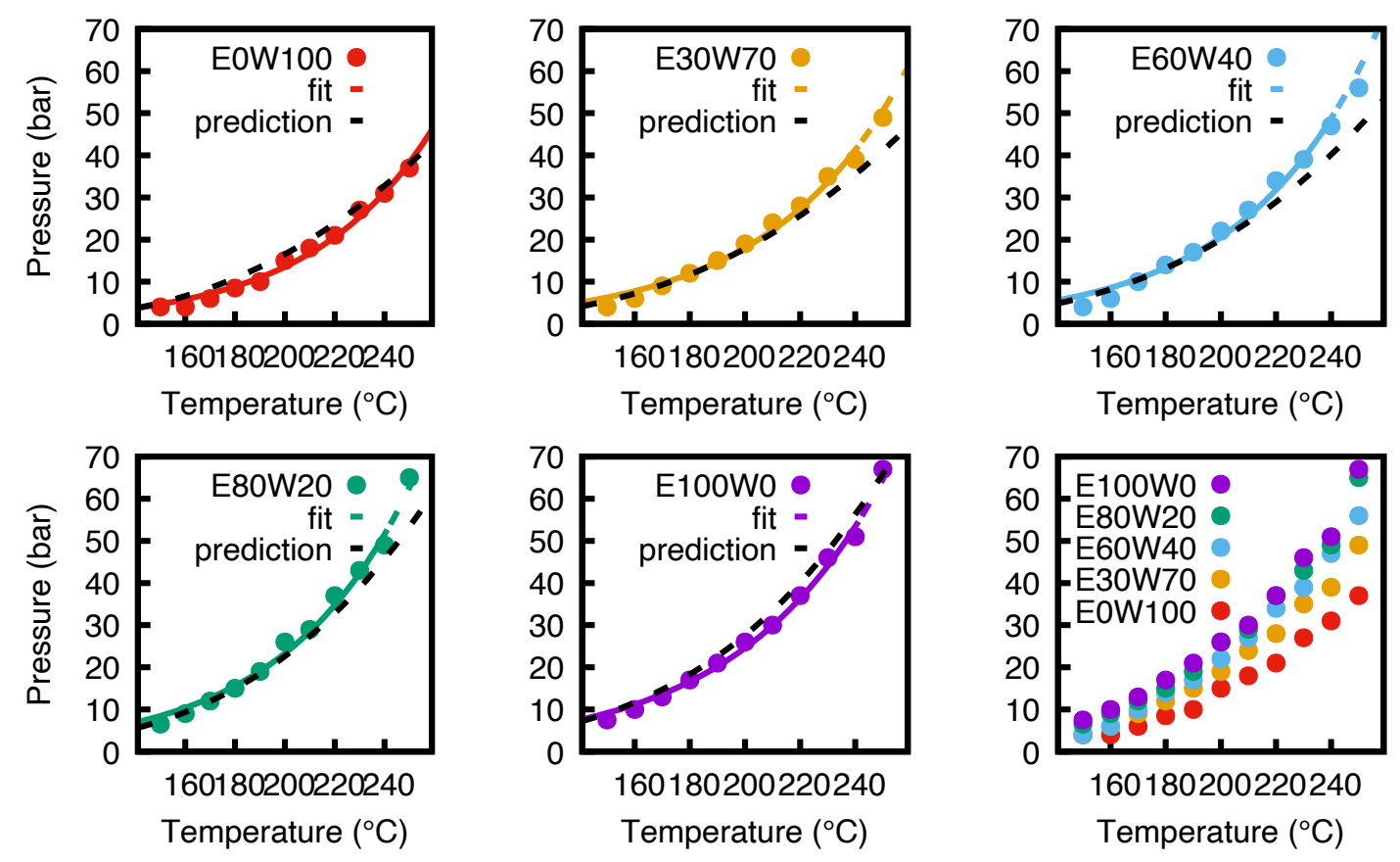

Figure 7: Pressure build-up inside the autoclave as a function of temperature for the different solvents. The full lines are best fits with Antoine equation and the dotted ones predicted evolutions from tabulated parameters. ${ }^{26}$ The bottom-right graph superposes all the experimental data.

Similar experiments have being carried out with the reactants and no significant autogenous pressure lowering was observed, in agreement with previous reports. ${ }^{28}$ If this pressure decrease exists, it lies within the measurement precision ( \pm 2 bars).

Pressure increase is beneficial to the synthesis as it increases the reactivity of the precursors ${ }^{29}$ and especially at the solid-liquid interface ${ }^{30}$ in the heterogeneous system composed of the layered titanate nano-rods $\mathrm{Na}_{2} \mathrm{Ti}_{3} \mathrm{O}_{7}$ (solid) and the barium ions $\mathrm{Ba}^{2+}$ in the solvent. The pressure thus improves both in situ exchange mechanisms: dissolution-precipitation and topotactic ions exchange in between the nano-rod layers. Even though pressure increases with the volume fraction of ethanol, (especially at $250^{\circ} \mathrm{C}$ where the pressure increase in pure ethanol is twice that of pure water), the resulting increased reactivity at the solid-liquid 
interface is not effective for E100W0 because $\mathrm{Ba}(\mathrm{OH})_{2}$ is not soluble in ethanol. With a water-ethanol solvent, pressure is a "soft action" parameter in the solvo-thermal synthesis as the amount of energy required to increase pressure by 70 bar (i.e the maximum pressure increase in Figure 7) corresponds to a decrease of less than one degree ${ }^{31}$ in the autoclave. Pressure is therefore not the key parameter controlling nano-particle morphogenesis.

\section{Temperature}

Increasing temperature enhances the reaction as it induces a better solubility of $\mathrm{Ba}(\mathrm{OH})_{2}$ inside the water volume fraction of the solvent and increases the mobility of the dissolved species, most importantly $\mathrm{Ba}^{2+}$ but also $\mathrm{OH}^{-}, \mathrm{Na}^{+}$and $\mathrm{CO}_{3}{ }^{2-}$ coming from the residual carbon dioxide gas dissolved in water.

Another effect of temperature is to modify the permittivity of the solvent. ${ }^{32}$ This changes the mutual reactivity of dissolved ions interacting through Coulomb forces. The decrease of the solvent static permittivity as a function of the molar fraction of ethanol $\left(x_{\mathrm{EtOH}}\right)$ can be plotted from the data in Ref. 33 (see Figure S7). Heating from $20^{\circ} \mathrm{C}$ to $80^{\circ} \mathrm{C}$ decreases significantly the value of the static relative permittivity (by about $25 \%$ to $32 \%$ ) for all ethanol molar fractions. The initial reactivity in all solvent mixtures therefore decreases on heating. Consistent with the established "soft parameter" role of pressure in solvo-thermal syntheses, the pressure in the autoclave increases marginally the permittivity for all solvents (by less than $2.5 \%$, up to $250^{\circ} \mathrm{C}$ ), see Supporting Information and Fig S8 and S9. The influence of pressure on the reactivity is also negligible compared to the influence of the ethanol molar fraction (Figure $\mathrm{S} 8$ ) and the temperature (Figure S9].

In summary, temperature is the key parameter in solvo-thermal syntheses. It decreases the permittivity for all solvent compositions. Pressure is only a soft (though necessary) parameter. The mutual reactivity of reactants is thus maximal, for every solvent, at the beginning of the synthesis and decreases gradually during the synthesis process.

As a consequence, the syntheses should be near completion at the end of the heating ramp 
before the holding time. To verify this hypothesis, one additional synthesis is performed with the E60W40 solvent, but this time the heat treatment is interrupted at $250^{\circ} \mathrm{C}$ (i.e. at the end of the heating ramp) by quenching the autoclave to room temperature under compressed air. This gives access to the synthesis state at the end of the heating ramp. X-ray diffraction indeed shows that $\mathrm{BaTiO}_{3}$ is formed (see Figure S10). However, the nano-particles size and morphology are very different from the nano-cubes obtained after the 24 hour temperature plateau.

At the end of the heating ramp to $250^{\circ} \mathrm{C}$, only some nano-tori are present with other round-shaped nano-particles (Figure S11). Nano-tori are the major thermodynamically stable shapes obtained after the $24 \mathrm{~h}$ temperature plateau, but at $200^{\circ} \mathrm{C}$ (Figure 3). The difference in the morphology of the nano-objects before and after the temperature plateau comes from the fact that at the end of the heating ramp, the remaining nano-tori have not had yet enough time to undergo the merging-rebuilding process (described in Ref. 34) leading to the formation of nano-cubes. It is therefore mainly during the holding time that $\mathrm{BaTiO}_{3}$ nano-particles merge or self-rebuild in order to obtain thermodynamically stable shapes corresponding to the temperature and pressure of the plateau.

A solvo-thermal synthesis therefore unfolds in three parts: first the synthesis of the product during the heating ramp, second, the nano-particles self-building completion in their final thermodynamically stable shape during the temperature plateau, third the cooling part simply allowing to recover well-shaped nano-particles.

\section{Nature of the solvent}

\section{Solvent viscosity}

The physico-chemical of the solvents can be thought of as having a potential crucial influence on the size and morphology of the nano-particles. The viscosity of water-ethanol solvents, in particular, has been studied extensively. It does not evolve monotonically between the values

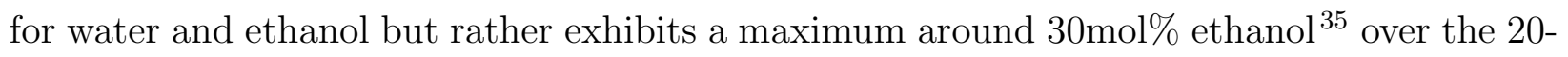


$50^{\circ} \mathrm{C}$ range. As, in solvo-thermal processes, pressure varies concomitantly with temperature, the influence of combined pressure and temperature are of particular interest. The studies of Refs. 36 (up to $350 \mathrm{MPa}$ at $25^{\circ} \mathrm{C}$ ), 37 (up to $120 \mathrm{MPa}$ and from 10 to $75^{\circ} \mathrm{C}$ ) and 38 (up to $40 \mathrm{MPa}$ and $345^{\circ} \mathrm{C}$ ) conclude that the viscosity of water-ethanol mixtures increases almost linearly with pressure and that its maximum shifts to higher ethanol concentration with temperature and pressure. The results presented in Fig.5 show that the viscosity, though it may have an influence over the reaction, is not enough to explain the difference in size and morphology of the synthesized nano-objects when all reactants are soluble in all constituents of the solvents.

In order to explain how the solvent composition influences the shape and morphology of the synthesised nano-objects, the structure of the solvent mixture as a hydrogen-bond (H-bond) network has to be considered, as well as the influence of adding reactants into it.

\section{The H-bonds network in the ethanol-water mixtures}

The structural properties of alcohol-water mixtures and their physical properties have been investigated for over 50 years. $\frac{39}{39}$ More recently, the physical properties of pure (with no reactants) water-ethanol mixtures have been extensively studied by molecular dynamics (see e.g. Refs. 40 43). These studies confirm experimental data on alcohol-water mixtures $\frac{44}{47}$ and highlight the respective roles of the hydrophobic (the $\mathrm{CH}_{3} \mathrm{CH}_{2}$ alkyl chain) and hydrophilic parts (the $\mathrm{OH}$ alcohol function) of the ethanol molecules.

In a water-ethanol mixture where water is the majority component, the ethanol molecules create micelles with the alkyl chains oriented toward the center leaving the $\mathrm{OH}$ alcohol groups available to form hydrogen bonds with surrounding water molecules. The ethanol and its first hydration shell therefore form a clathrate. $\underline{48}$

In water-ethanol mixtures three types of H-bonds coexist: water-water (three-dimensional), water-ethanol, and ethanol-ethanol (two-dimensional) $\stackrel{42}{42}^{\mathrm{Ab}}$ initio $\underline{49}$ and molecular dynamic $\underline{40}$ simulations point out to a stabilization $(-0.5 \mathrm{kcal} / \mathrm{mol})$ of the mixture of pure systems (water- 
water and ethanol-ethanol, the latter being the more bonded) when hetero-dimers (waterethanol) are formed. In pure liquid water, dipole-dipole interactions between molecules result in a percolating network of inter-connected H-bonds. $\frac{50151}{5 h e n}$ ethanol is added, water-ethanol H-bonds are formed and water molecules loose their tetrahedral structure. This decreases the amplitude of their dipole moment and explains the solvents' permittivity decrease when the alcohol molar fraction increases (Figure S7 and S8, ).

While the H-bond network in pure water percolates, molecular dynamics results ${ }^{43152}$ indicate that it is not the case in pure ethanol. The proton mobility in ethanol is a random Poisson process ${ }^{53}$ rather than mediated by H-bonds as proposed by the Grotthus mechanism for pure water. $\underline{54}$ When water and ethanol are mixed, ethanol and water molecules do not combine to generate a new H-bond network percolating throughout the entire solvent mixture. $\underline{40}$

As a summary, in water-ethanol mixtures, the H-bond network in ethanol does not percolate and the ethanol molecules self-organize in clusters due to their hydrophobic parts. They are surrounded by a hydration shell beyond which they do not influence the percolating network of H-bonds between water molecules.

A particular molar fraction of ethanol arises from simulations: $\underline{41} x_{\mathrm{EtOH}}=0.3$ (the conversion between volume fractions used up to now and molar fractions (relative to the total volume of solvent) is given by Eq.S2 and illustrated in Fig S6). This threshold value determines the type of clusters present in the water-ethanol mixtures: above this threshold, water clusters are formed by H-bonding to surrounding ethanol molecules clumping together their $\mathrm{CH}_{3} \mathrm{CH}_{2}$ hydrophobic groups (see Figure 8, right). Below this threshold, small isolated

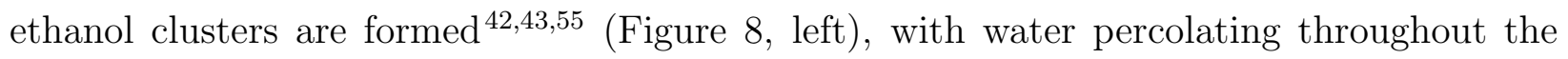
mixture in water-water H-bonded filament-like clusters which are then attached to clumped ethanol molecules by the free OH-links. This topological difference indicates that the major mechanism of H-bonding is driven by water. These clusters are not a static feature of the solvents and therefore a precise definition of their size cannot be assigned. Such dynamic 
nature has has been probed, e.g. through the Brownian motion of polysterene beads in water-ethanol mixtures. $\underline{56}$
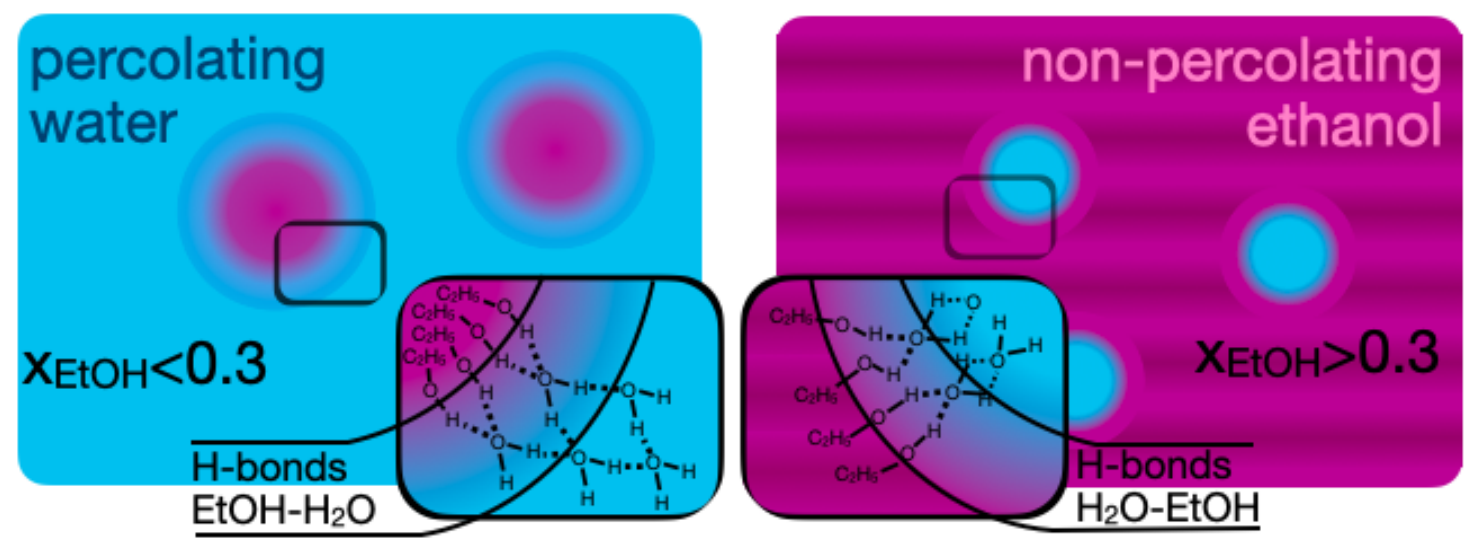

Figure 8: For $\mathrm{x}_{\mathrm{EtOH}}<0.3$ (left), ethanol clusters in percolating water, with an enlargement on the first hydration shell where the $\mathrm{CH}_{3} \mathrm{CH}_{2}$ alkyl chains of ethanol create H-bonds with the water molecules of the first hydratation shell. For $\mathrm{x}_{\mathrm{EtOH}}>0.3$ (right), water forms clusters ("nano-reactors") in ethanol where the H-bond network does not percolate. The enlarged panels shows the first hydration shell where the H-bonds are created between water and ethanol.

The influence of temperature (from -13 to $250^{\circ} \mathrm{C}$ ) and pressure on the structure of the H-bond networks of water-alcohol mixtures (over the full composition range) can be obtained from room-temperature molecular dynamics simulations through the reverse Kirkwood-Buff integral method. ${ }^{[57}$ Methanol rather than ethanol is often used in calculations because its hydrophobic group $\left(\mathrm{CH}_{3}\right)$ is simpler and less demanding in calculation times than the one of ethanol $\left(\mathrm{CH}_{3} \mathrm{CH}_{2}\right)$.

The self-preference of water increases with rising temperatures in both water- and methanolrich mixtures, reaching a limiting value near the critical point of methanol $\left(240^{\circ} \mathrm{C}, 79 \mathrm{bar}\right)$. The methanol self-preference in methanol-rich mixtures is weak due to the hydrophobic effect. Rapid equilibrium among the various hydrogen-bonded structures takes place in all these mixtures. The same is supposed to be true for the H-bonds interactions between water and ethanol molecules, especially as ethanol has a similar critical point $\left(241^{\circ} \mathrm{C}, 63 \mathrm{bar}\right)$. Above ethanol critical point (i.e. in the supercritical region of its phase diagram), ethanol clusters form and disappear dynamically. This corresponds to the two ethanol-rich solvent 
compositions E80W20 and E100W0 at $250^{\circ} \mathrm{C}$ and $\mathrm{P}>63$ bars.

\section{Interaction between ions and $\mathrm{H}$-bonds network.}

The presence of reactants complicates the description of the H-bond network in the solvents as $\mathrm{Ba}^{2+}$ and $\mathrm{OH}^{-}$ions are released from $\mathrm{Ba}(\mathrm{OH})_{2}$ in water, in addition to the $\mathrm{CO}_{3}{ }^{2-}$ anions resulting from the dissolution of $\mathrm{CO}_{2}$ gas in water.

During the synthesis of $\mathrm{BaTiO}_{3}$ nano-particles, the bidirectional topotactic ion exchange reaction ${ }^{58}$ promotes the diffusion of $\mathrm{Na}^{+}$from $\mathrm{Na}_{2} \mathrm{Ti}_{3} \mathrm{O}_{7}$ to the solvent mixture and decreases the quantity of free $\mathrm{Ba}^{2+}$ in the water part of the solvent.

These shifting concentrations of ions interact with water molecules through ion hydration, i.e. ion-dipole interactions. Hydration involves H-bond formation different from that in pure water, making a hydration shell around the ions. This first hydration shell is surrounded by other water molecules that are therefore not directly bounded to the ion, slightly oriented, and being exchanged rapidly with the rest of the solution on one side, and slowly with the hydration shell molecules on the other side.

However, the question of the influence of dissolved ions on the water structure beyond their hydration shell remains. The experimental Hofmeister series ${ }^{\sqrt{59}}$ ranks the anion influence on the surrounding water molecules, ranging from stabilization (kosmotropes) or "water structure makers" to disruption (chaotropes) or "water structure breakers". These concepts are related to the H-bond network stability and are therefore relevant for our study.

According to this series the $\mathrm{CO}_{3}{ }^{2-}$ and $\mathrm{OH}^{-}$present in the solvent, and which are not involved in the synthesis of $\mathrm{BaTiO}_{3}$, are kosmotropic anions and so have the ability to order water molecules beyond their immediate hydration shell.

Conversely, the kosmotropic character of cations can be established combining references 
60 and 61:

$$
\begin{aligned}
& \left(\mathrm{CH}_{3}\right)_{4} \mathrm{~N}^{+}>\left(\mathrm{CH}_{3}\right)_{2} \mathrm{NH}^{2+}>\mathrm{K}^{+} \approx \mathrm{Na}^{+}> \\
& \left.\quad \mathrm{Cs}^{+}>\mathrm{Li}^{+}>\mathrm{NH}_{4}^{+}>\mathrm{Mg}^{2+}>\mathrm{Ca}^{2+}>\mathrm{Ba}^{2+} \gg \mathrm{C}^{2} \mathrm{NH}_{2}\right)^{3+}
\end{aligned}
$$

From this series, the cations present in the solvent $\left(\mathrm{Na}^{+}\right.$and $\left.\mathrm{Ba}^{2+}\right)$ should not disturb the H-bonds of water except in the hydration shell and thus will not prevent the existence of water and ethanol clusters in the various mixtures.

Now that the H-bond networks of the solvents and the influence of the dissolved ion species present as reactants is established, the influence of the solvent composition (above or below the percolation threshold) on the synthesis of $\mathrm{BaTiO}_{3}$ can be studied.

\section{$\mathrm{BaTiO}_{3}$ synthesis in solvents below the percolation threshold $\left(x_{\mathrm{EtOH}}<0.3\right)$}

Two of the solvents investigated here are below the percolation threshold: E0W100 $\left(x_{\mathrm{EtOH}}=0\right)$ and E30W70 $\left(x_{\mathrm{EtOH}}=0.116\right)$. The water-rich regions of the solvents are characterized by the persistence of a three-dimensional water H-bond network that percolates throughout the mixture while ethanol remains in small isolated clusters. The free flow of the barium ions through the water volume of these solvents drive simultaneously, under solvo-thermal conditions, the deposition-reaction of the $\mathrm{Ba}^{2+}$ and the topotactic ions exchange with the $\mathrm{Na}^{+}$ ions as well as the nano-particle growth.

This free flow of barium through the water H-bonds percolative pathways (Figure 8) enables the synthesis of individual rounded nano-shapes in pure water (E0W100) and, as for all solvent compositions, the higher the temperature the larger the nano-objects (Figure 3). At the highest temperature $\left(250^{\circ} \mathrm{C}\right)$, individual elongated shapes up to several hundred nanometers long are even observed. When ethanol is added at concentrations below the percolation threshold (i.e. in E30W70), agglomerated round-shaped slightly-smaller nanoobjects are also observed. This underlines the importance of the solvent composition and 
the corresponding extension of the water H-bond network, especially as the molarities of the reactants are close: $0.1 \mathrm{M}$ in E0W100 and 0.14 M in E30W70.

\section{$\mathrm{BaTiO}_{3}$ synthesis in solvents above the percolation threshold $\left(x_{\mathrm{EtOH}}>\mathbf{0 . 3}\right)$}

Above the percolation threshold, the situation is reversed: ethanol breaks the percolative water network and water clusters are formed. The water-clusters size depends on the ethanol volume fraction: the more ethanol, the smaller the water clusters. As the barium precursor is only soluble in water, it is trapped in these clusters where the synthesis of $\mathrm{BaTiO}_{3}$ occurs. The water clusters therefore constitute "nano-reactors" (Figure 8).

The E100W0 $\left(x_{\mathrm{EtOH}}=0.965\right)$, E80W20 $\left(x_{\mathrm{EtOH}}=0.551\right)$, and E60W40 $\left(x_{\mathrm{EtOH}}=0.315\right)$ are the solvents above the percolation threshold. The E60W40 solvent is very close to the percolation threshold; it therefore hosts water clusters that are larger than for the two other solvents (E80W20 and E100W0) that are further away from the percolation thresh-

old. This larger size maintains the molarity of the precursor low enough $(0.25 \mathrm{M})$ to exceed the nucleation-aggregation stage, resulting in a rich variety of well-shaped individual nanoparticles as tori, cubes, spheres etc. from $200^{\circ} \mathrm{C}$ to $250^{\circ} \mathrm{C}$. For solvents further away from the percolation threshold (E80W20 and E100W0), the smaller size of the water clusters and the consequent higher molarity of the barium precursor limit the reaction to the nucleationaggregation stage, producing smaller nano-objects.

\section{Conclusion}

Solvo-thermal syntheses of ferroelectric nano-particles of $\mathrm{BaTiO}_{3}$ are carried out in waterethanol solvents with varying volume fractions, from pure water to pure ethanol. One precursor is only soluble in water $\left(\mathrm{Ba}(\mathrm{OH})_{2} \cdot 8 \mathrm{H}_{2} \mathrm{O}\right.$ ) whereas the other (solid $\mathrm{Na}_{2} \mathrm{Ti}_{3} \mathrm{O}_{7}$ ) is present throughout the solvent. Identical quantities of precursors are used in each solvent mixtures.

The synthesis of $\mathrm{BaTiO}_{3}$ is already achieved at the end of the heating ramp. The sub- 
sequent temperature plateau enables the nano-particles to acquire their final, thermodynamically stable, shapes and sizes. A rich variety of crystalline $\mathrm{BaTiO}_{3}$ nano-structures are obtained at the end of the process: nano-tori, nano-cubes, nano-spheres as well as elongated shapes, either separated from each other or agglomerated, depending on the temperature of the plateau (24h) and solvent composition.

Increasing the temperature of the plateau enhances the solubilizing power of the solvents as well as the ions mobility in the different solvent mixtures. Heating also increases the autogenous pressure. Both contribute to the synthesis of individual nano-objects. The pressure improves both in situ exchange mechanisms: dissolution-precipitation and topotactic ion exchange. It acts as a "soft" but necessary parameter compared to the predominant influence of temperature (and solvent composition).

A particular molar fraction of ethanol exists in water-ethanol mixtures: $x_{\mathrm{EtOH}}=0.3$ determining the alcohol concentration threshold below which ethanol clusters exist while water percolates throughout the entire volume. Above this value, water clusters, which can be considered as "nano-reactors", exist and ethanol does not percolate.

To obtain specific shapes of individual nano-objects (cubes, tori), the solvent composition has to correspond to an ethanol molar fraction above the percolation threshold and the higher the temperature the less agglomerated the nano-objects. Close to the percolation threshold, larger water clusters (lower molarity of the barium precursor) form and the nanoobjects adopt their thermodynamically stable shapes (tori, cubes...). Further away from the concentration threshold, smaller clusters (higher molarity) form and the reaction is restricted to the nucleation-aggregation stage, producing mainly nano-cubes. Extended to a general principle, in order to harness the full potential of a solvent mixture in a solvo-thermal synthesis, reactants molarity must be calculated with respect to the solvent in which they are soluble rather than to the total volume of the solvent mixture.

Below the concentration threshold, only elongated shapes, at best mixed with nanospheres are obtained. 
Understanding the role of the solvent in the solvo-thermal synthesis of nano-objects requires inputs from chemistry, physics, and molecular dynamic simulations but enables to tune the final aspects of the nano-objects.

The key point is that even in a mixture of fully miscible liquids, the local heterogeneities of the solvent are a powerful tool to control the shape and size of the synthesized nano-objects.

\section{Experimental}

\section{Solvo-thermal synthesis of $\mathrm{BaTiO}_{3}$}

The filling factor (ratio of the volume of liquid over total volume) of the autoclave is 0.55 for all syntheses of $\mathrm{BaTiO}_{3}$. The de-ionized water is degassed by boiling for $1 \mathrm{~h}$ and then cooled to $4^{\circ} \mathrm{C}$. Then it is saturated with $\mathrm{N}_{2}$ gas as described in Ref. 62. This technique allows to decrease drastically the formation of $\mathrm{BaCO}_{3}$. After stirring, the mixtures $\left(\mathrm{Ba}(\mathrm{OH})_{2} \cdot 8 \mathrm{H}_{2} \mathrm{O}\right.$ and $\mathrm{Na}_{2} \mathrm{Ti}_{3} \mathrm{O}_{7}$ ) are put into a Teflon vessel for 30 min under $\mathrm{N}_{2}$ atmosphere and transferred into the Teflon lined autoclave. The solvo-thermal syntheses are performed at 150, 200, and $250^{\circ} \mathrm{C}$ under autogenous pressure during $24 \mathrm{~h}$. The products are washed with de-ionized water until the $\mathrm{pH}$ of the filtrate is neutral, and finally collected in ethanol and dried in an oven at $70^{\circ} \mathrm{C}$ for $12 \mathrm{~h}$.

\section{Characterization of the materials}

X-ray diffraction (Brüker D2 Phaser with Cu radiation source and X-Flash Detector) is used for phase identification, diffraction peak fittings are performed with the Topas (Brüker AXS) software. Scanning (SEM Leo Gemini 1530 FEG) and transmission (TEM Jeol $120 \mathrm{keV}$ ) electron microscopy observations are performed on TEM grids with conducting lacey carbon films (300 mesh). 


\section{Supporting Information Available}

Additional SEM images; X-ray characterisation of $\mathrm{BaTiO}_{3}$; Molarity of the solvents; Size determination: comparison of the apparent crystallite and grain sizes; Synthesis of $\mathrm{BaTiO}_{3}$ in the E0W100 solvent with a molarity of $0.25 \mathrm{M}$; Ethanol volume fraction vs ethanol molar fraction; Variation of the permittivity of the solvents as a function of temperature; Influence of pressure on the static relative permittivity of the solvents; Characterization of the $\mathrm{BaTiO}_{3}$ nano-objects synthesized at the end of the heating stage.

\section{References}

(1) Arno, M. C.; Inam, M.; Weems, A. C.; Li, Z.; Binch, A. L. A.; Platt, C. I.; Richardson, S. M.; Hoyland, J. A.; Dove, A. P.; O’Reilly, R. K. Exploiting the role of nanoparticle shape in enhancing hydrogel adhesive and mechanical properties. Nature Communications 2020, 11, 1420.

(2) Chen, C.; Wylie, R. A. L.; Klinger, D.; Connal, L. A. Shape Control of Soft Nanoparticles and Their Assemblies. Chemistry of Materials 2017, 29, 1918-1945.

(3) Hinde, E.; Thammasiraphop, K.; Duong, H. T.; Yeow, J.; Karagoz, B.; Boyer, C.; Gooding, J. J.; Gaus, K. Pair correlation microscopy reveals the role of nanoparticle shape in intracellular transport and site of drug release. Nature Nanotechnology $\mathbf{2 0 1 7}$ 12, 81-89.

(4) Tak, Y. K.; Pal, S.; Naoghare, P. K.; Rangasamy, S.; Song, J. M. Shape-Dependent Skin Penetration of Silver Nanoparticles: Does It Really Matter? Scientific Reports 2015, 5, 1-11.

(5) Anoufa, M.; Kiat, J. M.; Kornev, I.; Bogicevic, C. Energy harvesting in core-shell ferroelectric ceramics: Theoretical approach and practical conclusions. Journal of Applied Physics 2013, 113, 054104. 
(6) Kiat, J. M.; Bogicevic, C.; Karolak, F.; Dezanneau, G.; Guiblin, N.; Ren, W.; Bellaiche, L.; Haumont, R. Low-symmetry phases and loss of relaxation in nanosized lead scandium niobate. Physical Review B 2010, 81, 144122.

(7) Anoufa, M.; Kiat, J. M.; Kornev, I.; Bogicevic, C. Vortices of polarization in BaTiO3 core-shell nanoceramics: Calculations based on ab initio derived Hamiltonian versus Landau theory. Physical Review B 2013, 88, 144106.

(8) Thorner, G.; Kiat, J.-M.; Bogicevic, C.; Kornev, I. Axial hypertoroidal moment in a ferroelectric nanotorus: A way to switch local polarization. Physical Review B 2014, 89, 220103.

(9) Prosandeev, S.; Ponomareva, I.; Kornev, I.; Bellaiche, L. Control of Vortices by Homogeneous Fields in Asymmetric Ferroelectric and Ferromagnetic Rings. Physical Review Letters 2008, 100, 047201.

(10) Prosandeev, S.; Bellaiche, L. Controlling Double Vortex States in Low-Dimensional Dipolar Systems. Physical Review Letters 2008, 101, 097203.

(11) Bogicevic, C.; Thorner, G.; Karolak, F.; Haghi-Ashtiani, P.; Kiat, J.-M. Morphogenesis mechanisms in the solvothermal synthesis of BaTiO 3 from titanate nanorods and nanotubes. Nanoscale 2015, 7, 3594-3603.

(12) Prosandeev, S.; Bellaiche, L. Hypertoroidal moment in complex dipolar structures. Journal of Materials Science 2009, 44, 5235-5248.

(13) Koruza, J.; Kodumudi Venkataraman, L.; Malič, B. Magnetic, Ferroelectric, and Multiferroic Metal Oxides; Elsevier, 2018; pp 51-69.

(14) Shvartsman, V. V.; Lupascu, D. C. Lead-Free Relaxor Ferroelectrics. Journal of the American Ceramic Society 2012, 95, 1-26. 
(15) Bobic, J. D.; Vijatovic Petrovic, M. M.; Stojanovic, B. D. Magnetic, Ferroelectric, and Multiferroic Metal Oxides; Elsevier, 2018; pp 233-249.

(16) Huang, Y.; Zhao, C.; Wu, B.; Wu, J. Multifunctional BaTiO 3 -Based Relaxor Ferroelectrics toward Excellent Energy Storage Performance and Electrostrictive Strain Benefiting from Crossover Region. ACS Applied Materials \& Interfaces 2020, 12, 2388523895.

(17) Yang, Y.; Ji, Y.; Fang, M.; Zhou, Z.; Zhang, L.; Ren, X. Morphotropic Relaxor Boundary in a Relaxor System Showing Enhancement of Electrostrain and Dielectric Permittivity. Physical Review Letters 2019, 123, 137601.

(18) Yarbrough, R.; Davis, K.; Dawood, S.; Rathnayake, H. A sol-gel synthesis to prepare size and shape-controlled mesoporous nanostructures of binary (II-VI) metal oxides. $R S C$ Advances 2020, 10, 14134-14146.

(19) Rosbottom, I.; Ma, C. Y.; Turner, T. D.; O’Connell, R. A.; Loughrey, J.; Sadiq, G.; Davey, R. J.; Roberts, K. J. Influence of Solvent Composition on the Crystal Morphology and Structure of p -Aminobenzoic Acid Crystallized from Mixed Ethanol and Nitromethane Solutions. Crystal Growth \& Design 2017, 17, 4151-4161.

(20) Biacchi, A. J.; Schaak, R. E. The Solvent Matters: Kinetic versus Thermodynamic Shape Control in the Polyol Synthesis of Rhodium Nanoparticles. ACS Nano 2011, 5, 8089-8099.

(21) Kolen'ko, Y. V.; Kovnir, K. A.; Gavrilov, A. I.; Garshev, A. V.; Frantti, J.; Lebedev, O. I.; Churagulov, B. R.; Van Tendeloo, G.; Yoshimura, M. Hydrothermal synthesis and characterization of nanorods of various titanates and titanium dioxide. Journal of Physical Chemistry B 2006, 110, 4030-4038.

(22) Yang, J.; Geng, B.; Ye, Y.; Yu, X. Stick-like titania precursor route to MTiO $3(\mathrm{M}=$ Sr, Ba, and Ca) polyhedra. CrystEngComm 2012, 14, 2959-2965. 
(23) Ávila, H. A.; Ramajo, L. A.; Reboredo, M. M.; Castro, M. S.; Parra, R. Hydrothermal synthesis of $\mathrm{BaTiO} 3$ from different Ti-precursors and microstructural and electrical properties of sintered samples with submicrometric grain size. Ceramics International 2011, 37, 2383-2390.

(24) Feng, Q.; Hirasawa, M.; Yanagisawa, K. Synthesis of crystal-axis-oriented BaTiO3 and anatase platelike particles by a hydrothermal soft chemical process. Chemistry of Materials 2001, 13, 290-296.

(25) Lee, D. K.; Cho, I. S.; Lee, S. W.; Kim, D. H.; Shim, H. W.; Kim, D. W.; Hong, K. S. Low-temperature synthesis of phase-pure 0D-1D BaTiO3 nanostructures using H2Ti3O7 templates. European Journal of Inorganic Chemistry 2010, 1343-1347.

(26) NIST, NIST Standard Reference Database Number 69. 2016.

(27) Mies, M. J.; Rebrov, E. V.; Jansen, J. C.; de Croon, M. H.; Schouten, J. C. Hydrothermal synthesis of a continuous zeolite Beta layer by optimization of time, temperature and heating rate of the precursor mixture. Microporous and Mesoporous Materials 2007, 106, 95-106.

(28) Kapoor, K. A Textbook of Physical Chemistry: Applications of Thermodynamics (SI Units), Vol.3, 4th ed.; McGraw Hill Education (India) Private Limited, 2015.

(29) Rørvik, P. M.; Grande, T.; Einarsrud, M.-A. One-Dimensional Nanostructures of Ferroelectric Perovskites. Advanced Materials 2011, 23, 4007-4034.

(30) Walton, R. I. Subcritical solvothermal synthesis of condensed inorganic materials. Chemical Society Reviews 2002, 31, 230-238.

(31) Equating the energy corresponding to a temperature change $\Delta T$ ( $\rho . V . C_{p} \Delta T$, with $\rho$ the density, $V$ the volume, $C_{p}$ the isobaric specific heat capacity) to the one corresponding to a change of pressure $\Delta P\left(-\beta . V\left(P_{f}^{2}-P_{i}^{2}\right) / 2\right)$, with $\beta$ the compressibility, and $P_{f}, P_{i}$ the 
final and initial pressures) brings, at room temperature, $\Delta T \simeq-3 \mathrm{mK}$ for pure water and $\Delta T \simeq-14 \mathrm{mK}$ for pure ethanol. In water-ethanol mixtures, only compressibility does not evolve monotonically (see e.g. S.A. Parke and G.G. Birch Food Chemistry 1999, 67, 241-246), but $|\Delta T|$ remains below $25 \mathrm{mK}$ for all compositions and up to $100^{\circ} \mathrm{C}$.

(32) Fang, C. S.; Chen, Y. W. Preparation of titania particles by thermal hydrolysis of TiCl4 in n-propanol solution. Materials Chemistry and Physics 2003, 78, 739-745.

(33) Åkerlöf, G. Dielectric constants of some organic solvent-water mixtures at various temperatures. Journal of the American Chemical Society 1932, 54, 4125-4139.

(34) Bogicevic, C.; Thorner, G.; Karolak, F.; Haghi-Ashtiani, P.; Kiat, J. M. Morphogenesis mechanisms in the solvothermal synthesis of BaTiO3 from titanate nanorods and nanotubes. Nanoscale 2015, 7, 3594-3603.

(35) Khattab, I. S.; Bandarkar, F.; Fakhree, M. A. A.; Jouyban, A. Density, viscosity, and surface tension of water+ethanol mixtures from 293 to 323K. Korean Journal of Chemical Engineering 2012, 29, 812-817.

(36) Thompson, J. W.; Kaiser, T. J.; Jorgenson, J. W. Viscosity measurements of methanol-water and acetonitrile-water mixtures at pressures up to 3500bar using a novel capillary time-of-flight viscometer. Journal of Chromatography A 2006, 1134, 201-209.

(37) Tanaka, Y.; Matsuda, Y.; Fujiwara, H.; Kubota, H.; Makita, T. Viscosity of (water + alcohol) mixtures under high pressure. International Journal of Thermophysics 1987, $8,147-163$.

(38) Ono, T.; Kyoda, M.; Amezawa, R.; Ota, M.; Sato, Y.; Inomata, H. Measurement and correlation of density and viscosity of $\mathrm{n}$-alcohol-water mixtures at temperatures up to $618 \mathrm{~K}$ and at pressures up to $40 \mathrm{MPa}$. Fluid Phase Equilibria 2017, 453, 13-23. 
(39) Franks, F.; Ives, D. J. G. The structural properties of alcohol-water mixtures. Q. Rev. Chem. Soc. 1966, 20, 1-44.

(40) Ghoufi, A.; Artzner, F.; Malfreyt, P. Physical Properties and Hydrogen-Bonding Network of Water-Ethanol Mixtures from Molecular Dynamics Simulations. Journal of Physical Chemistry B 2016, 120, 793-802.

(41) Mijaković, M.; Kežić, B.; Zoranić, L.; Sokolić, F.; Asenbaum, A.; Pruner, C.; Wilhelm, E.; Perera, A. Ethanol-water mixtures: Ultrasonics, Brillouin scattering and molecular dynamics. Journal of Molecular Liquids 2011, 164, 66-73.

(42) Zhong, Y.; Patel, S. Electrostatic polarization effects and hydrophobic hydration in ethanol-water solutions from molecular dynamics simulations. Journal of Physical Chemistry B 2009, 113, 767-778.

(43) Noskov, S. Y.; Lamoureux, G.; Roux, B. Molecular dynamics study of hydration in ethanol-water mixtures using a polarizable force field. Journal of Physical Chemistry B 2005, 109, 6705-6713.

(44) Egashira, K.; Nishi, N. Low-Frequency Raman spectroscopy of ethanol-water binary solution: Evidence for self-association of solute and solvent molecules. Journal of Physical Chemistry B 1998, 102, 4054-4057.

(45) Dixit, S.; Crain, J.; Poon, W. C.; Finney, J. L.; Soper, A. K. Molecular segregation observed in a concentrated alcohol-water solution. Nature 2002, 416, 829-832.

(46) Dixit, S.; Soper, A. K.; Finney, J. L.; Crain, J. Water structure and solute association. 2002, 59, 377-383.

(47) Guo, J. H.; Luo, Y.; Augustsson, A.; Kashtanov, S.; Rubensson, J. E.; Shuh, D. K.; Ågren, H.; Nordgren, J. Molecular structure of alcohol-water mixtures. Physical Review Letters 2003, 91, 1-4. 
(48) Frank, H. S.; Evans, M. W. Free volume and entropy in condensed systems III. Entropy in binary liquid mixtures; Partial molal entropy in dilute solutions; Structure and thermodynamics in aqueous electrolytes. The Journal of Chemical Physics 1945, 13, $507-532$.

(49) Fileti, E. E.; Chaudhuri, P.; Canuto, S. Relative strength of hydrogen bond interaction in alcohol-water complexes. Chemical Physics Letters 2004, 400, 494-499.

(50) Sciortino, F.; Geiger, A.; Stanley, H. E. Effect of defects on molecular mobility in liquid water. Nature 1991, 354, 218-221.

(51) Sciortino, F.; Geiger, A.; Stanley, H. E. Network defects and molecular mobility in liquid water. The Journal of Chemical Physics 1992, 96, 3857-3865.

(52) Gereben, O.; Pusztai, L. Cluster formation and percolation in ethanol-water mixtures. Chemical Physics 2017, 496, 1-8.

(53) Morrone, J. A.; Tuckerman, M. E. Ab initio molecular dynamics study of proton mobility in liquid methanol. Journal of Chemical Physics 2002, 117, 4403-4413.

(54) de Grotthuss, C. Annales de Chimie, ou Recueil des mémoires concernant la chimie et les arts qui en dépendent, et spécialement la pharmacie; 1806; pp 54-73.

(55) Dougan, L.; Bates, S. P.; Hargreaves, R.; Fox, J. P.; Crain, J.; Finney, J. L.; Réat, V.; Soper, A. K. Methanol-water solutions: A bi-percolating liquid mixture. Journal of Chemical Physics 2004, 121, 6456-6462.

(56) Furukawa, K.; Judai, K. Brownian motion probe for water-ethanol inhomogeneous mixtures. The Journal of Chemical Physics 2017, 147, 244502.

(57) Marcus, Y. Preferential solvation in mixed solvents Part 8. Aqueous methanol from sub-ambient to elevated temperatures. Physical Chemistry Chemical Physics 1999, 1, 2975-2983. 
(58) A.D. Smigelkas,; E.O. Kirkendall, Zinc diffusion in alpha brass. Trans. AIME 1947, $171,130-142$.

(59) Kunz, W.; Henle, J.; Ninham, B. W. 'Zur Lehre von der Wirkung der Salze' (about the science of the effect of salts): Franz Hofmeister's historical papers. Current Opinion in Colloid and Interface Science 2004, 9, 19-37.

(60) Marcus, Y. Effect of Ions on the Structure of Water: Structure Making and Breaking. Chemical Reviews 2009, 109, 1346-1370.

(61) Hall, G. M., Ed. Methods of Testing Protein Functionality; Springer US: Boston, MA, 1996.

(62) Kesavan, P. C.; Sharma, G. J.; Afzal, S. M. J. Differential Modification of Oxic and Anoxic Radiation Damage by Chemicals: I. Simulation of the Action of Caffeine by Certain Inorganic Radical Scavengers. Radiation Research 1978, 75, 18.

\section{Acknowledgement}

This work is supported by a public grant overseen by the French National Research Agency (ANR) as part of the "Investissements d'Avenir" program (reference: ANR-10-LABX-0035, Labex NanoSaclay). 